\title{
FORMAÇÃO CONTÍNUA DE PROFESSORES DE FÍSICA EM ANGOLA: INOVAR PELA AVALIAÇÃO DOS ALUNOS
}

\author{
FORMACIÓN CONTINUA DE PROFESORES DE FÍSICA EN \\ ANGOLA: INNOVAR POR LA EVALUACIÓN DE LOS ALUMNOS
}

\section{IN SERVICE EDUCATION OF PHYSICS TEACHERS IN ANGOLA: INNOVATING TROUGH STUDENTS'ASSESSMENT}

\author{
Maria da Graça Breganha ${ }^{1}$ \\ Nilza Costa ${ }^{2}$ \\ Betina da Silva Lopes ${ }^{3}$
}

${ }^{1}$.Instituto Nacional de Investigação e Desenvolvimento INIDE. Luanda. Angola.

${ }^{2}$.Universidade de Aveiro. Portugal.

${ }^{3}$.Universidade de Aveiro. Portugal. Universidade de Coimbra, Portugal

Resumo O estudo foca um programa de formação contínua (PFC) de professores de Física, centrado na reconstrução de conceções e práticas de avaliação dos alunos, numa escola secundária angolana. O PFC teve a duração aproximada de um ano, e 11 professores participaram no mesmo. O PFC foi conceptualizado na integração de diversas recomendações emergentes da literatura. O objetivo principal deste artigo consiste em analisar o PFC desenvolvido, nomeadamente quanto aos seus efeitos na mudança de concepções e práticas de avaliação de professores formandos, e ainda quanto às potencialidades, dificuldades e constrangimentos encontrados. Metodologicamente, recorreu-se a uma abordagem de estudo de caso, envolvendo três dos professores participantes. Recolheram-se dados por questionários, entrevistas, análise documental de registos dos formandos e alunos, gravação vídeo, notas das investigadoras, e ainda uma reflexão individual feita pelos professores dois anos após a formação. A análise de dados foi essencialmente análise de conteúdo, embora se tenha recorrido também à estatística descritiva. Os resultados mostram mudanças nas concepções e práticas dos professores, mas também constrangimentos, principalmente contextuais (por exemplo, absentismo dos alunos às aulas). Por fim, delineiam-se recomendações específicas para Formação Contínua de professores no país e para a investigação. Palavras-chave: Avaliação interna dos alunos; Ensino da Física; FormaÇão de ProfesSORES em serviço; Desenvolvimento Profissional. 
Resumen El estudio se centra en un programa de formación continua (PFC) de profesores de Física, centrado en la reconstrucción de concepciones y prácticas de evaluación de los alumnos, en una escuela secundaria Angolana. El PFC tuvo una duración aproximada de un año, habiendo participado en él 11 profesores. El PFC fue conceptualizado en la integración de diversas recomendaciones emergentes de la literatura. El objetivo principal de este artículo consiste en analizar el PFC desarrollado, en particular en cuanto a sus efectos en el cambio de concepciones y prácticas de evaluación de profesores formandos, y aún en cuanto a las potencialidades, dificultades y limitaciones encontradas. Metodológicamente se recurrió a un enfoque de estudio de caso, involucrando a tres de los profesores participantes. Se recopilaron datos por cuestionarios, entrevistas, análisis documental de registros de los alumnos y alumnos, grabación de vídeo, notas de las investigadoras, y de una reflexión individual hecha por los profesores dos años después de la formación. El análisis de datos fue análisis de contenido e estadística descriptiva. Los resultados muestran cambios en las concepciones y prácticas de los profesores, pero también limitaciones, principalmente contextuales Por último, se esbozaron recomendaciones específicas para Formación Continua de profesores en el país y para la investigación.

Palabras claves: Evaluación interna de los alumnos; Enseñanza de la física; Formación De Profesores; en Servicio; Desarrollo Profesional.

Abstract The study focuses on a continuous training program (CTP) of physics teachers, centered on the reconstruction of conceptions and practices of student assessment, in an Angolan secondary school. The CTP lasted approximately one year, with 11 teachers participating in it. The CTP was conceptualized based on recommendations from the literature. The main objective of this article is to analyze the developed CTP, namely its effects on the change of conceptions and practices of assessment of the teachers, as well as the potentialities, difficulties and constraints. Methodologically, a case study approach involving three of the participating teachers was used. Data were collected by questionnaires, interviews, documentary analysis of trainee and student records, video recording, researcher's notes, and an individual reflection by the teachers two years after the training. Data analysis was essentially content analysis, although descriptive statistics were also used. The results show changes in the conceptions and practices of the teachers, but also constraints, mainly contextual (for example, absenteeism of students to classes). Finally, specific recommendations for Continuing Teacher Training in the Country and for research are outlined.

Keywords: Learning Processes; Assessment methods; Physics Education; Teacher Education; Professional Training.

\section{INTRODUÇÃo}

A importância de se investir na formação contínua de professores (FCP) tem sido reconhecida internacionalmente, estando refletida, por exemplo, na Agenda 2030 da UNESCO (UNESCO, 2016), e na Agenda 2063 da União Africana (União Africana, 2015). Em 
Angola, existe vontade política para a dinamização intensiva da FCP (INFQE, 2016). No entanto, as iniciativas continuam aquém das necessidades identificadas (MEA, 2014; LOPES, COSTA e MATIAS, 2016), o que evidencia a relevância deste estudo.

Este artigo descreve e analisa um programa de formação contínua (PFC) de professores de Física, intitulado "O Ensino da Física no contexto da reforma curricular em Angola: o papel da avaliação das aprendizagens dos alunos como catalisador da mudança das práticas", na modalidade presencial e à distância (50h presenciais e 50h à distância), desenvolvido, implementado, monitorizado e avaliado numa escola pública do ensino secundário em Angola, no alinhamento da preocupação acima referida. O tema central do PFC foi a avaliação dos alunos, utilizada como motor de mudança em concepções e práticas dos professores, uma vez que, segundo vários autores (por exemplo, DENEEN \& BROWN, 2006; ECCLESTONE \& PRYOR, 2003; ROLDÃO \& FERRO, 2015), a avaliação desempenha um papel central no desenvolvimento do processo de ensino e aprendizagem, podendo potenciá-lo e, por conseguinte, promover o sucesso dos alunos. Se bem que o nosso estudo se tenha centrado na FCP, argumentos quanto à relevância da avaliação dos alunos para as concepções e práticas dos professores são também referidas para o caso da formação inicial (por exemplo, NASCIMENTO, BARBOSA \& OLIVEIRA, 2017).

O PFC implementado foi concebido com base em cinco pressupostos $(\mathrm{P})$ e que emergiram da literatura sobre PFC, no nosso caso, de uma forma integrada. Apresentam-se, de seguida, cada um desses pressupostos e, para cada um deles, exemplos de estudos em que se sustentaram.

Assim, o PFC:

P1 - foi desenvolvido em contexto, isto é diretamente articulado com as práticas profissionais dos professores (por exemplo, GONÇALVES, 2011);

P2 - almejava mudança não só nas concepções dos professores, mas também nas suas práticas (por exemplo, SILVA \& MORTIMER, 2003);

P3 - partiu sempre dos saberes e experiências prévias dos professores (por exemplo, VILLANI \& PACCA, 1997);

P4 - envolveu diferentes fases, uma das quais deve incluir a concepção, implementação e avaliação de projetos inovadores nas salas de aulas dos professores, em particular a seguir a uma primeira fase em que se discutem concepções e práticas (por exemplo, REBELO, 2014):

P5 - procurou desenvolver não só conhecimentos, mas também atitudes nos professores, em particular atitudes de autonomia na (co)construção de conhecimento sobre as suas práticas (por exemplo, CRÓ, 2005).

Com base nos pressupostos enunciados, e no contexto em que o PFC se iria desenvolver, o Quadro 1 apresenta uma síntese do PFC, em termos das suas três fases - I, II e III (indicando-se número de horas presenciais e à distância de cada uma), objetivos formativos e principais tarefas realizadas. 


\begin{tabular}{|c|c|c|}
\hline $\begin{array}{l}\text { Fase (Período de realiza- } \\
\text { ção e horas/h - presen- } \\
\text { ciais e à distância) }\end{array}$ & Objetivos formativos & $\begin{array}{c}\text { Principais tarefas } \\
\text { (nota: algumas das tarefas desenvol- } \\
\text { vem-se em mais do que uma fase) }\end{array}$ \\
\hline $\begin{array}{l}\text { I } \\
\text { (março a maio de } 2015 ; \\
12 \mathrm{~h} \text { presenciais }-14 \mathrm{a} \\
17 \text { de março, e } 15 \mathrm{~h} \text { à } \\
\text { distância) }\end{array}$ & $\begin{array}{l}\text { - Comprometer e responsa- } \\
\text { bilizar os formandos com o } \\
\text { PFC; } \\
\text { - Promover a consciencia- } \\
\text { lização de conhecimentos e } \\
\text { saberes (teóricos e práticos) } \\
\text { prévios dos formandos sobre } \\
\text { avaliação dos alunos; } \\
\text { - Desenvolver esses conhe- } \\
\text { cimentos e saberes à luz da } \\
\text { investigação e do quadro } \\
\text { normativo nacional. }\end{array}$ & $\begin{array}{l}\text { - Apresentação, discussão e negocia- } \\
\text { ção do PFC (Fase I); } \\
\text { - Partilha de conhecimentos e saberes } \\
\text { prévios sobre avaliação dos alunos } \\
\text { em aulas de Física (Fase I); } \\
\text { - Apresentação pela formadora, e re- } \\
\text { flexão com os formandos, de conhe- } \\
\text { cimentos teóricos e normativos sobre } \\
\text { avaliação dos alunos (Fase I); } \\
\text { - Concepção de projetos a serem } \\
\text { implementados em turmas dos pro- } \\
\text { fessores, com enfoque na inovação } \\
\text { das práticas de avaliação dos alunos } \\
\text { (Fase I); } \\
\text { - Elaboração de um diário reflexivo } \\
\text { (DR) sobre o percurso formativo } \\
\text { (Fase I, II e III). }\end{array}$ \\
\hline $\begin{array}{l}\quad \text { II } \\
\text { (maio a dezembro de } \\
\text { 2015; 26h presenciais - } \\
21 \text { a } 27 \text { de maio 2015, e } \\
\text { 25h à distância) }\end{array}$ & $\begin{array}{l}\text { - Aprofundar os saberes pro- } \\
\text { fissionais, em particular atra- } \\
\text { vés da mudança de concep- } \\
\text { ções e práticas de avaliação } \\
\text { dos alunos no contexto de } \\
\text { sala de aula; } \\
\text { - Promover atitudes críticas } \\
\text { e reflexivas sobre as práticas } \\
\text { de ensino, nomeadamente de } \\
\text { avaliação; }\end{array}$ & $\begin{array}{l}\text { - Implementação e avaliação dos } \\
\text { projetos em sala de aula de Física } \\
\text { (Fase II); } \\
\text { - Análise, com a formadora e seus } \\
\text { pares, dessa implementação e avalia- } \\
\text { ção (Fases I e II). }\end{array}$ \\
\hline $\begin{array}{l}\text { III } \\
\text { (janeiro a março de } \\
2016,12 \mathrm{~h} \text { presenciais - } \\
1 \text { a } 5 \text { de março de 2016, } \\
\text { e } 10 \mathrm{~h} \text { à distância) }\end{array}$ & $\begin{array}{l}\text { - Desenvolver atitudes de } \\
\text { coautoria na construção de } \\
\text { conhecimentos e saberes } \\
\text { profissionais. }\end{array}$ & $\begin{array}{l}\text { - Construção e disseminação de co- } \\
\text { nhecimentos e saberes desenvolvidos, } \\
\text { em particular através da organização } \\
\text { e participação de umas Jornadas Pe- } \\
\text { dagógicas a nível provincial (Fase } \\
\text { III); } \\
\text { - Elaboração de um balanço global } \\
\text { sobre a formação a incluir no DR } \\
\text { (Fase III). }\end{array}$ \\
\hline
\end{tabular}

Sem minimizar a relevância das três fases do programa de formação e dos respetivos objetivos, atendendo à maior duração da Fase II quer em número de horas, 51 horas no total, quer em meses, nove meses, apresenta-se a título exemplificativo, na Figura 1, um registro de sala de aula de um dos professores formandos do estudo de caso. A figura ilustra a apresentação, por um grupo de alunos, de uma atividade que lhes foi proposta no âmbito 
do subtema D9- Dinamómetros, do Tema D - Força e Massa, do Programa de Física da 7. classe de Angola.

Figura 1- Trabalho de Grupo em contexto de sala de aula da $70^{a}$ classe (incluindo a fase II do PFC)

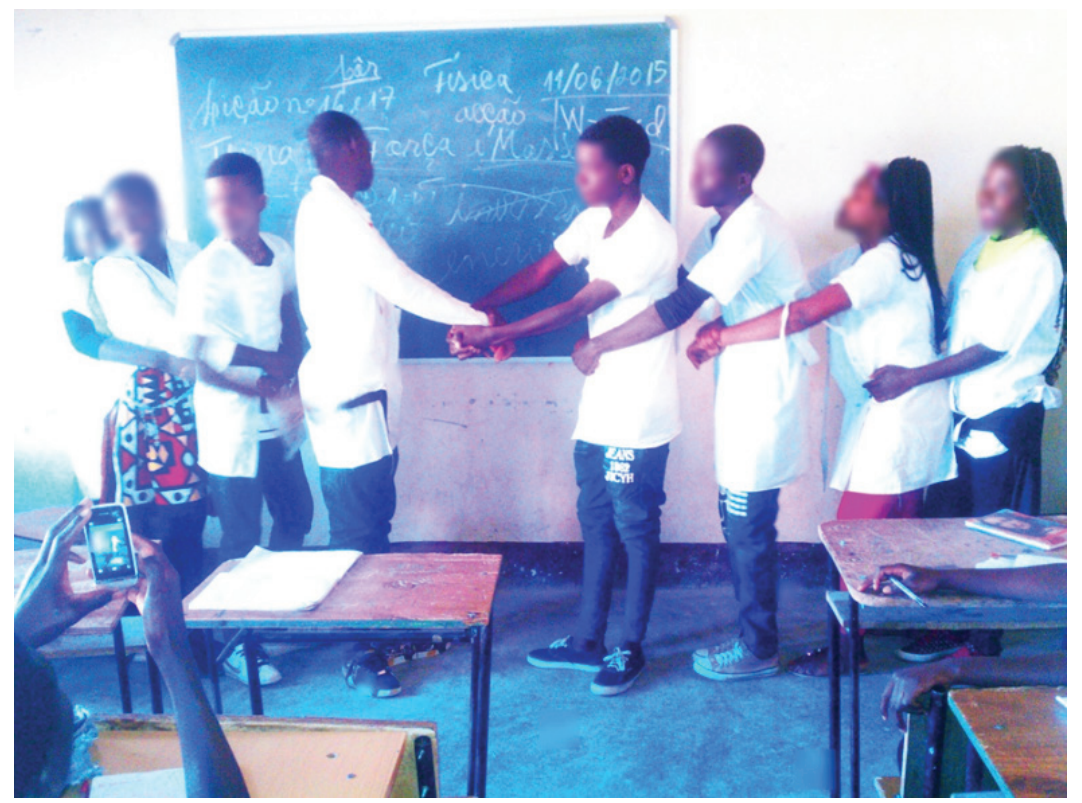

Este artigo estrutura-se em partes principais. Para além desta Introdução, segue-se o Desenvolvimento do estudo, que inclui a explicitação dos objetivos e questões de investigação, a Metodologia e a Apresentação e discussão dos resultados. De seguida, apresentam-se as Conclusões do estudo, para o caso da FCP e para a investigação. Por fim, existe uma seção de Agradecimentos e outra com as Referências citadas ao longo do texto.

\section{Desenvolvimento}

\section{Objetivos e questões de investigação}

Este estudo tem como objetivo principal descrever e analisar o PFC desenvolvido, nomeadamente no que respeita i) aos efeitos que o mesmo teve na mudança de concepções e práticas de avaliação de um grupo de três formandos ('o caso'); ii) às potencialidades, dificuldades e constrangimentos encontrados, no sentido de delinear recomendações específicas, nomeadamente para a FC.

Foram definidas as seguintes questões de investigação:

QI: De que modo as concepções e práticas de avaliação dos três professores - formandos (e sua integração no processo de ensino e aprendizagem) se alterou com o PFC?

QII: Quais as principais potencialidades, dificuldades e constrangimentos encontrados ao longo do PFC, e de que forma podem ser ultrapassados no futuro? 


\section{Metodologia}

O PFC foi desenvolvido com um grupo de 11 professores de Física de uma escola pública da cidade de Lubango (Angola) na qual é ministrado o $1 .^{\circ}$ ciclo do ensino secundário (7. à 9. ${ }^{\mathrm{a}}$ classe). O município do Lubango está localizado na província de Huíla, com 776.249 habitantes, e um total de 54 escolas públicas que ministram aulas do $1 .^{\circ}$ ciclo do ensino secundário, envolvendo 113.000 alunos. ${ }^{1}$

A escola na qual foi desenvolvido o PFC foi escolhida a) pelos contatos pessoais e profissionais já existentes entre a primeira autora deste artigo, professora-investigadora responsável pelo PFC, e os professores de Física da Escola, nomeadamente com o coordenador do grupo disciplinar; e b) pelo seu contexto histórico. A professora-investigadora formou-se em Ciências da Educação/especialidade de Física no Instituto Superior de Ciências de Educação da Huíla, sediado na cidade do Lubango, e desde então tem mantido contato com escolas e professores de Física da província, em particular com os da escola selecionada para a realização deste estudo. A escola foi fundada durante a guerra angolana, para permitir que os estudantes deslocados completassem os seus estudos, mesmo quando já tivessem ultrapassado a idade máxima para a frequência escolar. A escola é composta por cinco edifícios associados, mas localizados em bairros diferentes, com uma distância aproximada de $5-7 \mathrm{~km}$ entre cada um.

O estudo enquadra-se no paradigma sociocrítico (COUTINHO, 2011), na medida em que parte da motivação em melhorar o ensino da Física por meio de uma intervenção específica, e contextualizada, designadamente o PFC. A cada uma das três fases do PFC está associada um ciclo de investigação com instrumentos de recolha de dados específicos, numa lógica de desenho investigativo emergente (GRAY, 2004). Desta forma, e em interação com o percurso formativo, o estudo assume características de investigação-ação, em que cada fase do PFC correspondeu a um ciclo investigativo. Por motivos de se poder ilustrar de uma forma mais qualitativa o estudo, e ainda da extensão permitida para o artigo, optou-se aqui por uma abordagem metodológica de estudo de caso, em que cada caso se refere ao percurso formativo de três professores participantes. Os critérios utilizados para a selecção dos três professores, de forma a tornar esta caso ilustrativo do $\mathrm{PFC}$, são apresentados mais à frente.

O Quadro 2 identifica os principais instrumentos de recolha de dados para cada uma das três fases do PFC, e ainda a recolha de dados feita dois anos apos a formação. A análise foi feita fundamentalmente por meio da técnica de análise de conteúdo, sendo esta complementada com análise estatística descritiva (por exemplo, análise de frequências para os dados constantes das fichas de presença dos formandos nas três fases do PFC, respostas dos alunos após a implementação dos projetos inovadores em sala de aula). Os critérios de

Para mais informação consultar: http://www.angop.ao/angola/pt_pt/noticias/educacao/2015/7/32/ Huila-Ministro-ensino-superior-destaca-papel-ISCED-formacao-quadros,ce83818c-9a3a-4759-959c-1 fd6a9b566e6. html; http://www.angop.ao/angola/pt_pt/noticias/educacao/2017/0/4/Huila-Professores-aguardam-por-reconversao-carreira, 1611 fe6b-6c84-4e03-ae52-b40920858273.html 
integração de cada um dos três professores deste estudo de caso encontram-se explicitados no Quadro 3.

Quadro 2-O PFC e a recolha de dados

\begin{tabular}{|c|l|}
\hline Fase do PFC & \multicolumn{1}{c|}{ Instrumentos de Recolha de dados } \\
\hline I & $\begin{array}{l}\text { Ficha de Caracterização Pessoal (FC); Ficha de expectativas e de Diagnóstico } \\
\text { Inicial (FE e DI); Observação participante (Notas de campo da investigadora } \\
\text { (NC)/e registo fotográfico (RF); Folha de presenças (FP) nas sessões presen- } \\
\text { ciais; Diários reflexivos (DR) dos formandos. }\end{array}$ \\
\hline II & $\begin{array}{l}\text { DR dos formandos, em particular com registros sobre a concepção, } \\
\text { implementação e avaliação em sala de aula dos projetos inovadores; } \\
\text { Observação participante (NC e RF); FP nas sessões presenciais; Entrevistas aos } \\
\text { formandos; Questionário aos alunos; Recursos produzidos pelos alunos. }\end{array}$ \\
\hline III & $\begin{array}{l}\text { Observação participante (NC e RF); FP nas sessões presenciais; Vídeo-grava- } \\
\text { ção das jornadas; Questionário de avaliação das jornadas aplicado aos partici- } \\
\text { pantes da mesma; DR dos formandos, em que se incluiu o balanço global do } \\
\text { PFC (DRgb). }\end{array}$ \\
\hline Fpós $\boldsymbol{a}$ & $\begin{array}{l}\text { Reflexão individual sobre o impacto da formação cerca de dois anos após } \\
\text { o seu término (RIp) }\end{array}$ \\
\hline
\end{tabular}

Quadro 3 - Critérios e indicadores para a escolha dos três professores do estudo de caso

A - Representatividade da participação no PFC

A1 - Em mais do que $75 \%$ das sessões presenciais;

A2 - Em sessões das três fases da formação

B - Comprometimento com a concepção, implementação e avaliação do projeto inovador (PI) em sala de aula:

B1- Concepção e implementação do PI em sala de aula evidenciados por registros (escritos, fotográficos, entre outros)

B2 - Avaliação do PI pelos alunos (aplicação de instrumentos sobre as aulas, e análise dos dados obtidos pelo professor formador)

C - Coautoria na produção de conhecimento profissional desenvolvido ao longo do PFC

Elaboração do DR (com descrições e reflexões de diferentes sessões, de cada uma das fases do PFP, e reflexão final sobre o mesmo)

D - Coautoria na disseminação de conhecimento profissional desenvolvido ao longo do PFC

Participação nas jornadas, com intervenções nas mesas-redondas (Fase III)

E - Envolvimento com o programa de investigação da formadora

Realização da entrevista no final da Fase II

F - Adequabilidade do perfil acadêmico do professor formando à docência

Maioritariamente com formação adequada (FAd) para o ensino da Física, embora pelo menos um professor de formação não adequada (FnAd)) 
Os quatro primeiros critérios usados na seleção dos professores foram definidos por evidenciarem a participação desejável na formação (por exemplo, assiduidade nas sessões presenciais, realização das principais tarefas propostas). O quinto critério foi incluído por evidenciar a atitude colaborativa dos professores com o projeto de investigação da professora-investigadora-formadora (primeira autora da comunicação), constituindo-se a realização da entrevista um elemento central para a mesma. Atendendo à realidade do contexto, onde existem professores a lecionar a disciplina de Física sem formação adequada para a mesma, em particular na escola em estudo, e embora seja desejável inverter esta situação, definiu-se um sexto critério que conduziu à escolha de um professor que não tivesse formação adequada para o ensino da Física (por exemplo, e no professor selecionado, em Economia).

Apresenta-se, no Quadro 4, o cumprimento dos seis critérios pelos professores selecionados. Embora fosse desejável que esses professores preenchessem todos os critérios, isso não foi possível numa situação, mas apenas num dos critérios, por razões de óbito de familiares. Contudo, esses três professores foram, de todos os participantes, aqueles que preencheram o maior número dos critérios. A cada um desses professores que constituem o caso ilustrativo foi dado um nome fictício, a saber: Professor Avunje; Professor Bondo e Professora Etiene.

Quadro 4 - Cumprimento (x) de cada critério, por professor

\begin{tabular}{|c|c|c|c|c|c|c|}
\hline \multirow[t]{2}{*}{ Professor-Formando } & \multicolumn{6}{|c|}{ Critérios } \\
\hline & $\mathbf{A}$ & $\mathbf{B}$ & $\mathbf{C}$ & D & $\mathbf{E}$ & $\mathbf{F}$ \\
\hline Avunje & $\begin{array}{l}\mathrm{A} 1-\mathrm{x} \\
\mathrm{A} 2-\mathrm{x}\end{array}$ & $\begin{array}{l}B 1-x \\
\text { B2 - }\end{array}$ & $\mathrm{X}$ & $\mathrm{x}$ & $\mathrm{x}$ & FAd \\
\hline Bondo & $\begin{array}{l}\mathrm{A} 1-\mathrm{x} \\
\mathrm{A} 2-\mathrm{x}\end{array}$ & $\begin{array}{l}\text { B1-x } \\
\text { B2-x }\end{array}$ & $\mathrm{x}$ & $\mathrm{x}$ & $\mathrm{x}$ & FAd \\
\hline Etiene & $\begin{array}{l}\mathrm{A} 1-\mathrm{x} \\
\mathrm{A} 2-\mathrm{x}\end{array}$ & $\begin{array}{l}B 1-x \\
B 2-x\end{array}$ & $\mathrm{x}$ & (óbito) & $\mathrm{X}$ & FnAd \\
\hline
\end{tabular}

\section{ApresentaÇão e discuSsão dos Resultados}

Nesta seção procede-se, num primeiro momento, à apresentação sumária e discussão dos resultados dos percursos formativos dos três professores-formandos, tendo em linha de conta a primeira questão de investigação enunciada. Num segundo momento, apresentam-se, e discutem-se, os resultados que procuram dar resposta à segunda questão de investigação, nomeadamente quanto às potencialidades, dificuldades e constrangimentos encontrados ao longo do PFC. Por fim, num terceiro momento, apresentam-se os resultados obtidos cerca de dois anos após a formação.

Atendendo à panóplia e quantidade de resultados obtidos, com consequência dos diferentes instrumentos usados na recolha de dados, mas também de diferentes atores participantes (professores, alunos, professora-investigadora-formadora), não é possível aqui apresentar em detalhe todos os resultados. Assim, a nossa opção foi a de caracterizar os 
principais resultados emergentes, em função das questões de investigação definidas, para cada um dos três professores-formandos e ilustrar os mesmos por meio do cruzamento de informação recolhida pelas diferentes fontes.

\section{UM PFC - tRES PERCURSOS DE DESENVOLVIMENTO DISTINTOS: "O SINGULAR NO COLETIVO/O COLETIVO NO SINGULAR"}

Apesar dos professores apresentarem perfis acadêmicos e profissionais diferentes, por exemplo, o Professor Bondo ter formação superior em ensino de Física e a Professora Etiene não possuir formação de base nem em Física nem para o ensino, os principais resultados emergentes do estudo sugerem as seguintes dimensões comuns, para os três professores, e cujas evidências se apresentam sumariamente no Quadro 5:

- apropriação global dos objetivos e fases do PFC, em função do planejado (por exemplo, a compreensão das três fases do programa e do que era pretendido em cada uma delas);

- mudanças de concepções e práticas de avaliação (por exemplo, ampliação da concepção de avaliação como classificação, importância da existência de diferentes momentos de avaliação, com feedback para os alunos em sala de aula, o contributo da avaliação para um maior conhecimento dos alunos), com implicações positivas para o processo de aprendizagem (por exemplo, aumento da sua motivação, reconhecimento da importância do momento de avaliação intermédio, com feedback descritivo, autoimplicação no processo de aprendizagem);

- melhoria das práticas profissionais, com reconhecimento do papel transformador da avaliação (por exemplo, os professores reconheceram que a nova forma de avaliar os alunos fez que eles passassem a ter um melhor conhecimento dos mesmos e, assim, aumentar o sucesso nas aprendizagens);

- principais contributos para essas mudanças (principais, no sentido de mais referidos) foram devidas nomeadamente à Fase II do PFC, isto é, quando os professores implementaram, refletiram e avaliaram os seus projetos inovadores;

- desenvolvimento profissional quanto à construção de conhecimento educativo. Esse resultado emergiu nos discursos de dois dos professores a propósito das suas vivências nas jornadas (Fase III). Apesar de alguma apreensão na preparação das mesmas, pensa-se que a intencionalidade formativa de fazer que professores formandos interviessem em mesasredondas durante as jornadas, colocando-os no papel de coautores do seu conhecimento profissional, teve um papel relevante no seu desenvolvimento profissional.

De mencionar, por fim, que algumas das dimensões que foram intencionalmente introduzidas no PFC (ver Quadro 1) passíveis de potenciar as mudanças desejadas, com sustentação na literatura, não surtiram o efeito desejado. Referimo-nos, em particular, ao papel:

- que a explicitação e negociação, com os alunos, dos critérios de avaliação no início do desenvolvimento das sequências didáticas dos projetos implementados em sala de aula, poderia desempenhar na orientação do processo de ensino, aprendizagem e avaliação;

- do desenvolvimento do trabalho autônomo e da supervisão entre pares, que poderia ter tido na transição da fase I para a II e nesta última, para a consolidação dessas mudanças; 
- dos DR, na potenciação de um posicionamento profissional crítico.

Assim, e embora cada professor tenha experienciado um percurso de desenvolvimento individual único, são de salientar, pelos resultados emergentes, as conquistas coletivas acima sumariadas, assim como, os fatores que para elas contribuíram. Para cada uma delas, e para cada um dos professores, são apresentados, no Quadro 5, exemplos ilustrativos retirados da informação recolhida por diferentes fontes. Para além das evidências individuais são ainda apresentadas evidências recolhidas, por exemplo, nas notas de campo da professora-investigadora-formadora, para a generalidade/todos dos/os professores formandos.

Quadro 5 - Evidências singulares extraídas de informação recolhida durante o PFC por resultado emergente ${ }^{2}$

\begin{tabular}{|c|c|}
\hline Professor & Apropriação global dos objetivos e fases do PFC \\
\hline Avunje & $\begin{array}{l}\text { "No dia } 14 \text { de Março do ano em curso a formadora apresentou o programa da for- } \\
\text { mação e um guião para a construção do Diário Reflexivo" (DRfb; Fase III); "Os } \\
\text { alunos vão fazendo relatórios de atividades laboratoriais e a avaliação vai ser } \\
\text { feita em duas fases" (DR, 28//05/15; Fase II) }\end{array}$ \\
\hline Bondo & $\begin{array}{l}\text { "Por fim o professor, apresentou o questionário aos alunos, solicitando-lhes que } \\
\text { respondessem, e realçando a importância das respostas sinceras ao mesmo" (DR; } \\
\text { Fase II) }\end{array}$ \\
\hline Etiene & $\begin{array}{l}\text { "Com a implementação do projeto pretende-se criar nos professores participantes } \\
\text { competência de avaliação das aprendizagens dos alunos em fisica" (DRgb; Fase } \\
\text { III) }\end{array}$ \\
\hline \multicolumn{2}{|r|}{ Evidências relatadas para a generalidade/todos dos/os professores } \\
\hline \multicolumn{2}{|c|}{$\begin{array}{l}\text { "(...) de um modo geral, os DR das sessões presenciais e os DRgb apresentavam uma descrição } \\
\text { detalhada do que se passou em cada sessão e fase do PFC" (NC, Fase I, II e III) }\end{array}$} \\
\hline Professor & $\begin{array}{c}\text { Mudança de concepções e práticas de avaliação, com implicações ao nível da } \\
\text { melhoria das aprendizagens dos alunos }\end{array}$ \\
\hline Avunje & $\begin{array}{l}\text { “(...) muitos de nós, professores, na avaliação temos pecado muito, no sentido de } \\
\text { atribuir (apenas) classificações e estas de forma não orientada." (E, Fase II); "(a } \\
\text { propósito da implementação do projeto em sala de aula) o aluno torna-se mais } \\
\text { criativo e capaz de vencer o medo de errar e mais intercativo com os colegas" } \\
\text { (DRgb, 24/09/15; Fase III); “(...) afinal de contas essa minha ideia era negativa } \\
\text { (...) O que se avalia é ter em conta não só a avaliação, é preciso saber o que é } \\
\text { que vou avaliar, e o que serve a avaliação. Então algo mudou em mim. Algo mu- } \\
\text { dou mesmo (...) eu constatei pelo menos que o que fiz vi, e que vale a pena conti- } \\
\text { nuar com esta proposta.” (DRbg, Fase III); "87\% dos alunos das classes do } 9^{\circ} D \text { D, } \\
\text { E e F acham que foi importante o professor ter feito a correção do trabalho, antes } \\
\text { da apresentação final (a propósito da análise feita pelo professor ao questionário } \\
\text { aplicado aos seus alunos no final da implementação do projeto)” (DR; Fase II). }\end{array}$ \\
\hline
\end{tabular}

2 (Legenda: AvJ - Resultados do questionário de avaliação das Jornadas aplicado a todos os seus participantes; DR - Diário Reflexivo; DRgb - Diário reflexivo global; E - entrevista; NC - Notas de campo da professora-investigadora-formadora; PPI - Planificação do projeto inovador). 


\begin{tabular}{|c|c|}
\hline Professor & Fatores que não contribuíram para mudanças \\
\hline Avunje & "Faltou apoio dos colegas na fase dos projetos (...)" (DR; Fase II). \\
\hline Bondo & $\begin{array}{l}\text { "Sobre os critérios de avaliação, o professor explicou aos alunos que o trabalho } \\
\text { seria avaliado; e essa avaliação iria contar com duas notas; a nota do trabalho } \\
\text { elaborado em geral e a nota da defesa" (DR, 22/08/15, Fase II). }\end{array}$ \\
\hline Etiene & $\begin{array}{l}\text { "(...) antes (nos momentos não presenciais no final da Fase I) estávamos confusos } \\
\text { de como elaborar as propostas didáticas, mas agora já estamos esclarecidos (após } \\
\text { a sessão de apresentação pela formadora de uma proposta didática inovadora" } \\
\text { (DR; } \mathbf{2 5 / 0 5 / 1 5 ) .}\end{array}$ \\
\hline & Evidências relatadas para a generalidade/todos dos/os professores \\
\hline \multicolumn{2}{|c|}{$\begin{array}{l}\text { "Embora as PPI apresentassem os critérios e indicadores a serem explicitados e negociados } \\
\text { com os alunos no início do projeto, e os mesmo terem sido discutidos com os professores no } \\
\text { inicio da fase II, apenas um dos professores os refere nos DR" (NC, Fase II e II) ; “(...) quan- } \\
\text { do a professora-investigadora-formadora iniciou as sessões presenciais da fase II deparou-se } \\
\text { com a ausência de propostas didáticas a implementar em sala de aula. Para ultrapassar este } \\
\text { constrangimento, optou-se por elaborar duas propostas didáticas e discutir as mesmas com os } \\
\text { professores" (NC; Fase II); “(...) Apesar de nos ter parecido, no início do PFC, a relevância } \\
\text { dos DR e da sua natureza, foi sendo necessário insistir muitas vezes com os professores para a } \\
\text { sua entrega atempada e, ainda, para o incremento de uma dimensão reflexiva e opinativa, e não } \\
\text { meramente descritiva e com reduzidas evidências. (...)" (NC, Fase I, II e III). }\end{array}$} \\
\hline
\end{tabular}

$\left(^{*}\right)$ eventualmente por a Professora Etiene não ter participado nas jornadas (por motivos de óbito) não se encontraram evidências.

Do referido nesta seção denota-se a perceção de ganhos reais por parte de cada um dos três professores como consequência do PFC, ganhos esses que, embora expressos em linguagens diferenciadas, espelham muitas semelhanças. Terminamos esta seção com um excerto da entrevista realizada com a Professora Etiene ilustrativo desses ganhos, e fazemo-lo por ser a docente sem formação em Física:

"Hoje já me sinto mais melhorada, me sinto com mais dignidade de dizer que sou professora de física do que antes porque antes eu limitava-me a copiar apenas do livro, mais agora já não, interatuo com os alunos".

\section{O 'CASTELO’ E AS SUAS “PEDRAS”}

Como potencialidades do PFC implementado destacam-se as seguintes, porque suportadas por evidências relativamente ao desenvolvimento profissional dos três professores em formação. É possível: i) mudar concepções e práticas de professores por meio de um percurso formativo centrado na avaliação das aprendizagens dos alunos, e assente na integração de pressupostos emergentes da literatura; ii) melhorar o processo de aprendizagem dos alunos, tornando-os mais motivados, participativos e comprometidos com o mesmo e iii) olhar os professores como autores (e coautores) do seu conhecimento profissional. 
De notar que esses resultados não só corroboram estudos realizados, por exemplo, por Santos e Pinto (2018), que realçam o papel estruturante da avaliação das aprendizagens dos alunos na melhoria das mesmas, e em particular do feedback fornecido (por exemplo, NASCIMENTO ET AL., 2017). Os resultados também evidenciam, em concordância com outros autores (por exemplo, ROLDÃO, 2017), que em processos de desenvolvimento profissional é fundamental dar voz aos professores e ao conhecimento por eles produzido.

Como dificuldades e constrangimentos do PFC implementado destacam-se as/os seguintes, porque também suportadas por evidências: i) dificuldades na demostração de autonomia profissional no desenvolvimento de projetos inovadores a implementar em sala de aula (no final da Fase I e início da Fase II); ii) dificuldades na dimensão da supervisão, vertical e horizontal, nos momentos de formação à distância. De referir que apesar da importância da política educativa nacional atribuída à supervisão pedagógica nas escolas, fortemente introduzida no contexto da reforma educativa (INFQ, 2011), estudos recentes (ver por exemplo, MANUEL \& BUZA, 2014) evidenciam a dificuldade da existência de práticas supervisoras nas escolas, em particular devido à falta de competências profissionais para o seu desempenho; iii) constrangimento provocado pela ausência da professora-investigadora-formadora nos momentos não presenciais da formação, em especial durante a concepção e implementação do projeto em sala de aula. Conforme escreve o Professor Bondo, no seu DR, houve uma "falta de acompanhamento durante a implementação".

Os maiores constrangimentos sentidos foram, contudo, de natureza contextual, em particular derivados: i) do absentismo dos alunos às aulas, o que dificultou a gestão do trabalho planejado (de grupo, por exemplo); ii) da falta de material didático (por exemplo, para operacionalizar em sala de aula a técnica dos três cartões "green, yellow, red" ilustrada pela formadora na Fase I, a exemplo do sugerido em DI (sem data); de equipamento laboratorial, o que fez a professora-investigadora-formadora disponibilizar um dinamômetro para cada uma das escolas anexas onde os professores participantes trabalhavam); iii) da falta de iniciativa e autonomia sentida pela formadora em momentos-chave do PFC, como foi o da concepção e implementação de projetos de sala de aula (final da Fase I e Fase II).

\section{E DEPOIS DO PFC ...}

Conforme o referido, cerca de dois anos após a formação, em setembro de 2018, solicitou-se aos professores uma reflexão individual por escrito sobre se o PFC que frequentaram teve implicações nas suas práticas profissionais mesmo após a sua conclusão, se sim quais, e se não por quê. No caso da resposta ter sido afirmativa, foram ainda solicitados exemplos específicos das práticas que ilustrassem as mudanças referidas.

Conforme se ilustra no Quadro 6, os três professores consideram que o PFC teve implicações mesmo após a sua conclusão (por exemplo, avaliar sem estar sempre a classificar, prestar mais atenção ao que os alunos fazem e dar-lhes feedback), tendo isso contribuído para que se tivessem tornado professores diferentes, tendo passado a contribuir mais para o sucesso dos seus alunos. Para além do que afirmam quanto ao impacto do PFC, os três 
professores deram exemplos concretos da continuação da utilização de estratégias de sala de aula resultantes da formação (por exemplo, uso de cartolinas, avaliação por fases, sendo algumas sem fins classificatórios).

Quadro 6 - Evidências singulares extraídas de informação recolhida após o PFC

\begin{tabular}{|c|c|}
\hline Professor & Fatores contribuíram para mudanças \\
\hline Avunje & $\begin{array}{l}\text { “A formação contribuiu para uma mudança significativa. Fez que eu melhorasse a } \\
\text { maneira de abordar ou de transmitir os conhecimentos. Antes da formação, só me } \\
\text { limitava a ditar os apontamentos e explicava o que não é correto. Atualmente, an- } \\
\text { tes de abordar um tema, procuro explorar os conhecimentos prévios que o aluno } \\
\text { sabe acerca do tema e analisar (...). Por exemplo, na } 7 .{ }^{\text {a }} \text { Classe; A Unidade } 3 \text { : Es- } \\
\text { trutura e Estados de Agregação das Substâncias; } 8 .{ }^{a} \text { Classe: Máquinas simples; } \\
\text { 9. }{ }^{a} \text { Classe: Eletrostática. Os conteúdos dessas unidades às vezes tenho dado para } \\
\text { os alunos abordarem em trabalho em grupo, porque os mesmos conteúdos refletem } \\
\text { o dia a dia do aluno. Para tal, (...) a elaboração do trabalho tem tido duas fases: } \\
\text { A primeira fase consiste na estruturação do trabalho e entregar ao professor para } \\
\text { corrigir, mas sem atribuir a classificação. A segunda fase consiste em elaborar o } \\
\text { trabalho final obedecendo às orientações do professor. (...) Antes eu só avaliava } \\
\text { com objetivo de atribuir uma classificação quantitativa. Atualmente tenho avalia- } \\
\text { do os alunos, tendo em conta assiduidade, participação nas aulas, realização das } \\
\text { atividades" (DRp; 5/9/18). }\end{array}$ \\
\hline Bondo & $\begin{array}{l}\text { "O programa de formação que frequentamos teve sim algumas implicações nas } \\
\text { minhas práticas profissionais, durante a formação, mesmo após a sua conclusão; } \\
\text { o PF deu-me mais horizontes no que toca às práticas de avaliação. (...). Já agora, } \\
\text { com a implementação de novas práticas, conseguimos orientar, motivar melhor } \\
\text { o aluno na busca do conhecimento de forma mais sólida e inspiradora. (...) Eu, } \\
\text { por exemplo, tenho implementado a cada ano letivo, para além dos trabalhos } \\
\text { individuais com frequência suficientemente orientados, trabalhos em grupo (...) } \\
\text { os resultados têm sido mais satisfatórios em comparação com os resultados tidos } \\
\text { anteriormente, antes da implementação das novas práticas de avaliação (...)" } \\
\text { (DRp; } \mathbf{3 0 / 0 9 / 1 8 )}\end{array}$ \\
\hline Etiene & $\begin{array}{l}\text { “(..) com o que aprendi no programa, tenho procurado ser uma boa professora } \\
\text { e pôr em prática alguns dos procedimentos aprendidos, como: uso das cartolinas } \\
\text { (...), fazer correção e não dar logo uma nota (...). Já não me vingo dos alunos, } \\
\text { aprendo com este programa de formação a dar mais atenção a eles. (...) quem re- } \\
\text { cebe uma formação muda a sua maneira de pensar e agir. (...) ”(DRp; 28/09/18). }\end{array}$ \\
\hline
\end{tabular}

\section{CONSIDERAÇõES FINAIS}

Considera-se que o estudo aqui apresentado traz contributos relevantes no sentido de orientar iniciativas, ainda hoje escassas na República de Angola (LOPES, COSTA \& MATIAS, 2016), na dinamização e intensificação de PFC de professores, na senha da vontade política existente (INFQE, 2016). Considera-se, ainda, que este estudo trouxe um aprofundamento conceptual sobre FCP, nomeadamente pela integração em cinco pressupostos de recomendações emergentes, porém de alguma forma isolada, na literatura. 
Num primeiro momento serão apresentadas orientações para a FCP, e num segundo serão indicadas sugestões para futuras investigações.

\section{ORIENTAÇÕES PARA A FCP}

Apresentam-se, de seguida três orientações para a FCP emergentes do estudo realizado:

$1^{\mathrm{a}}$ - Os pressupostos, que abaixo se sumariam, e que estiveram na base do desenvolvimento do nosso PFC, podem servir de orientação para a FCP. Segundo esses pressupostos, a FCP deve: i) ser desenvolvida em contexto, isto é, diretamente ligada às práticas profissionais dos professores; ii) almejar mudanças das práticas profissionais dos professores; iii) partir dos saberes e experiências prévias dos professores; iv) envolver os professores na concepção, implementação e avaliação de projetos inovadores nas suas aulas; v) desenvolver um sentido profissional no qual os professores podem (e devem) ser autores (e coautores) na construção de conhecimento sobre as suas práticas.

2. ${ }^{\mathrm{a}}$ - Continuar a abordar o tema da avaliação das aprendizagens em PFC, como catalisador de mudança de conceções e práticas de professores conducentes à melhoria do seu desempenho profissional. Embora o nosso PFC tenha sido desenvolvido para professores de Física, corrobora-se o que indica a literatura de que este tema pode ser abordado, na mesma perspetiva, noutras áreas disciplinares (por exemplo, SANTOS \& PINTO, 2018) e, ainda, transversalmente em PFC dirigidos a professor de diferentes áreas (ver, por exemplo, ROLDÃO \& FERRO, 2015).

3. - A manter-se uma modalidade mista (presencial e à distância) em PFC, a comunicação entre formandos e formadores deve ser coniventemente assegurada nos momentos não presenciais, por exemplo a partir da calendarização e análise de tarefas definidas para trabalho autônomo dos professores conforme sugere, por exemplo Pombo, Abelha, Caixinha, Marques \& Costa (2007).

\section{SUGESTÕES PARA INVESTIGAÇÕES FUTURAS}

Como sugestões para investigações futuras, refiram-se estudos a) de follow-up dos professores formandos que participaram no PFC, no sentido de aprofundar a compreensão da sustentabilidade das mudanças operadas após o término do mesmo, e b) de compreender formas de potenciar dimensões transversais do desempenho docente (como a cooperação e a supervisão entre pares), na medida em que estas são apontadas por diferentes autores (por exemplo, ABELHA, MACHADO \& COSTA-LOBO, 2014; MANUEL \& BUZA, 2014) como fundamentais para o desenvolvimento profissional do professor e, por conseguinte, o sucesso das aprendizagens dos alunos.

\section{AGRADECIMENTOS}

As autoras agradecem o apoio financeiro recebido pelos Fundos Nacionais através da FCT - Fundação para Ciência e Tecnologia, IP, no âmbito do projeto UID / CED / 00194/2013 financiados pela POCH, o Fundo Social Europeu e os Fundos Nacionais Portugueses do MEC. 


\section{REFERÊNCIAS}

ABELHA, Marta; MACHADO, Eusébio; COSTA-LOBO, Cristina. Colaboração docente em contexto educativo angolano: potencialidades e constrangimentos. In A. Lopes, M. Cavalcante, D. Oliveira \& A. Hyplito (Orgs.) Trabalho Docente e Formação: Políticas, Práticas e Investigação: Pontes para a mudança. Atas do II Encontro Luso-Brasileiro sobre o Trabalho Docente e Formação, (pp.5368-5380). Porto: CIIE Centro de Investigação e Intervenção Educativas, 2014.

COUTINHO, Clara. Metodologia de Investigação em Ciências Sociais e Humanas: teoria e Prática ( $2^{\mathrm{a}}$ edição). Coimbra: Almedina, 2011.

CRÓ, Maria de Lurdes. Formação de professores versus sucesso dos alunos. Revista Portuguesa de Pedagogia, Coimbra, v. 39, n.2, p. 313-338, 2005.

DENEEN, Cristopher; BROWN, Gavin The impact of conceptions of assessment on assessment literacy in a teacher education program. Congent Education, Local de publicação, v. 3, p. 122538, Oxfordshire, setembro, 2016.

DIFFERENTIATED INSTRUCTION PROJECT 2008-2009. Assessment for, as, of learning to support Differentiated Instruction. Use of choice cards to encourage student voice and empower student engagement and learning, sem data (Disponível em http://www.edugains.ca/resourcesDI/ProductsProjectSchools/DIProductsSecondaryProjects2009/1_Mathematics_A.pdf).

ECCLESTONE, Kathrin; PRYOR, John. 'Learning careers' or 'assessment careers? The impact of assessment systems on learning. British Educational Research Journal, v. 29, p. 471-488, Londres, 2003.

GONÇALVES, Lina Maria Alves. Formação Contínua de Professores em Contexto. Relatório de Estágio/Seminário para a obtenção de grau de Mestre nos Ensinos Básico e Secundário no Curso de Mestrado em Ensino de Educação Física e Desporto nos Ensinos Básico e Secundário, Lisboa (Portugal): Universidade Lusófona de Humanidades e Tecnologias, 2011.

GRAY, David. Doing research in the Real world. London: Sage, 2004.

INSTITUTO NACIONAL DE FORMACAÇÃO DE QUADROS - INFQ. Supervisão Pedagógica no Centro da Reforma Educativa em Angola. Luanda: INFQ, 2011.

INFQ. Proposta de Política de Formação de Professores da Educação Pré-escolar, do Ensino Primário e do I ciclo do Ensino Secundário. Luanda, INFQ, 2016. 
LOPES, Betina; COSTA, Nilza; MATIAS, Filipe. Impact evaluation of two master courses attended by teachers: an exploratory research in Angola. Problems of Education in the 21 st century, Vilnius, v. 74, p. 49-60, 2016.

LUCIA, Maria. A Visão do Professor quanto a critérios de avaliação, 2013. (Disponível em http://educere.bruc.com.br/ANAIS2013/pdf/9927 5962.pdf).

MANUEL, Ivanilson; BUZA, Alfredo. Supervisão escolar interna como instrumento de gestão das escolas, 2014. Disponível em buzaalfredo@yahoo.com.br www.aforges.org/ wp-content/uploads/2017/12/14-Supervisao-escolar-interna-como-instrumento.pdf).

MINISTÉRIO DE EDUCAÇÃO DE ANGOLA - MEA (2014). Exame nacional 2015 da Educação para Todos: Relatório de Monitorização sobre Educação para todos. Luanda: MEA, 2014.

NASCIMENTO, Mari Clair Moro, BARBOSA, Raquel Lazzari Leite e OLIVEIRA, Anelise Martinelli Borges de. Formação docente: contribuições da diversificação dos instrumentos avaliativos. Comunicações. Piracicaba, v. 24, n. 1, p. 149-169, 2017.

POMBO, Lúcia; ABELHA, Marta; CAIXINHA, Hélder; MARQUES, Luís; COSTA, Nilza. Formação contínua de professores de Ciências: de uma abordagem presencial para um contexto on-line. In J. B. Lopes e J.P. Cravino (Eds.), Relatos de práticas: a voz dos actores da Educação em Ciência em Portugal, Portugal. Vila Real: Minerva Transmontana, 98-102, 2007. (Disponível em: http://cms.ua.pt/eustdweb/Module00/XII_ENEC_paper 2007.pdf)

REBELO, Dorinda. Desenvolvimento profissional de professores de ciências: um estudo no contexto da geologia. Tese de Doutoramento em Didática e Formação/Ramo de Supervisão, Portugal (Aveiro): Universidade de Aveiro, 2014.

ROLDÃO, Maria. Formação de professores e desenvolvimento profissional. Revista de Educação PUC Campinas, Campinas, v. 22, n. 2, p. 191-202, 2017

ROLDÃO, Maria; FERRO, Nuno. O que é avaliar? Reconstrução de práticas e conceções de avaliação. Estudos em Avaliação Educacional, São Paulo, v. 26, n. 63, p. 570-594, 2015.

SANTOS, Cremiled; KROEFF, Renata. A contribuição do feedback no processo de avaliação formativa. Revista Multidisciplinar em Educação, Porto Velho, v. 5, n. 11, p. 20-39, 2018.

SANTOS, Leonor; Pinto, Jorge. Ensino de conteúdos escolares: A avaliação como fator estruturante. In F. Veiga (Coord.), O Ensino como fator de envolvimento numa escola para todos, p. 503-539. Lisboa: Climepsi Editores, 2018. 
SILVA, Penha Souza e MORTIMER, Eduardo Fleury. Formação continuada e mudanças nas práticas pedagógicas: o que dizem os professores de Química. In: Anais do IV Encontro Nacional de Pesquisa em Educação em Ciências (pp.1-11), Brasil (Bauru): UNESP, 2003.

UNESCO. Education 2030: Inchneon Declaration and Framework for Action towards inclusive and equitable quality education and lifelong learning for all. Paris, França: UNESCO, 2016.

UNIÃO AFRICANA. Agenda 2063: A África que queremos. Addis Ababa, Etiópia: African Union, 2015.

VILLANI, Alberto e PACCA, Jesuína Lopes. Construtivismo, Conhecimento Científico e Habilidade Didática no Ensino de Ciências. Revista da Faculdade de Educação da USP, S. Paulo, v. 23, n. 1/2, p. 196-214, 1997.

Dados dos AUTORAS

Maria da Graça Breganha

Doutoranda em Educação. Professora de Física. Professora de Física. Técnica Superior do Instituto Nacional de Investigação e Desenvolvimento, Luanda, Angola. mariadagraasoaresbreganha@yahoo.com.br

\section{Nilza Costa}

Professora Catedrática Aposentada da Universidade de Aveiro. Portugal.nilzacosta@ua.pt

\section{Betina da SiLva Lopes}

Doutora em Educação. Professora da Universidade de Coimbra. Portugal. blopes@ua.pt

Submetido em: 7-2-2019

Aceito em: 15-3-2019 